\title{
Management and utilization of uninhabited islands
}

\author{
Rui Li \\ Guangzhou huanshi east road 420 \\ Guangzhou Military Region Real Estate Board \\ Guangdong Guangzhou, China \\ 289141551@qq.com
}

\begin{abstract}
With the economic rapid development and the natural resource shortages, the state promote marine development strategy which make the management and utilization of uninhabited island becomes more and more important. Depending on the characteristics of uninhabited island's development and management, this article provides ideas and solutions for management to develop policies or take measures by researched and analyzed the related problems.
\end{abstract}

Keywords- uninhabited islands; development and utilization; effective management; ecological protection

\section{INTRODUCTION}

China's first comprehensive law on the island protection and management, "Island Protection Act", was implemented from March 1, 2010, which started the specification of uninhabited island's development and management [1]. With the economic rapid development and the shortage of the coastal areas' land resources, uninhabited island as a natural extension of the continental shelf and the inherent marine territory, its importance is increasingly apparent, and there are more and more development and utilization of the uninhabited islands.

However, compared with marine resources and land resources, it has a greater difference and unpredictability. Regardless of the development and utilization or day-to-day management, it lacks targeted research, and there are less programs and examples of specific mature development and utilization. In front of the current wave of development and utilization of marine resources, under the premise that how to protect the marine resources of renewable as much as possible, it has important practical significance to make full use of limited marine resources, doing theoretical research and pilot development exploration.

Since the uninhabited island is the outposts and bases of marine resources exploitation, and marine development mainly relying on the uninhabited island, we should pay more attention to strengthen controls of its management, protection, construction and utilization. But mostly uninhabited island is a special geographical unit [2], that we must clear understand its characteristics and constraints when developing the uninhabited island, the specific ideas see Figure 1.

\section{UNINHABITED ISLAND'S MANAGEMENT AND DEVELOPMENT CHARACTERISTICS}

\section{A. Fragile ecosystems}

The island is not only a nature's bounty, wildlife's paradise, and the ideal place for original travel, but also the cornerstone of defense outposts and maritime rights and interests. Compared with the land, the island area is small, and it has unique geographical environment. Especially for the non-residents island, transportation inconvenience and strong erosion of maritime climate make the construction of water, electricity, port and other infrastructure, as well as routine maintenance work need to invest a relatively large human and material resources, and follow-up continued investment will be more. In addition, because the island ecosystem is relatively independent and closed, its recovery capacity is weak for the ecological damage caused by the development and utilization process, once had a greater degree of damage, it can easily cause the total collapse of the entire ecosystem. And it will be easy to destroy the vegetation on the island, and even make devastating ecological damage to the island and marine life in surrounding waters with blindly disorder and reckless exploitation.

\section{B. Important strategic significance}

As an important part of the marine ecosystem, uninhabited island is the forward position of defense and a special area in China's economic development, which has special strategic significance. However, China attaches importance to land-based economy but neglect marine economy for years, leading to the development of the island use backward and can't take full advantage of huge marine resources [3].

With the implementation of the national strategy of the South China Sea, the importance of uninhabited island's development and utilization will be more apparent by firmly establish the principle of "national strategic objectives first" on the management and exploitation. Besides, must be sure to put the country's overall strategic benefits in a prominent place, and economic efficiency must unconditionally obey the country's overall strategic benefits. Establish the principle of national strategies can protect and support the development and utilization of marine resources from the system, as well as make full and effective development of marine resources and utilization and sustainability. 


\section{Poor regional economy}

The island economy is resource-based economy which based on the development of marine resources. The regional construction investment coefficient of uninhabited island is great for its facilities of life, transportation and communications are all blank, thus its regional construction investment is much greater than the general area [4].

In the long-term historical process of development, by the limitations of the natural, resource, economic, technical and other conditions, except a small number of big island with superior conditions, the vast majority of small and medium-sized island are fishing-based, living on inshore aquaculture or as supplies stations of oceanic fishing, supplemented by a small amount of farming; a few island with relatively abundant resources and advantageous location has seen rapid development of tourism industry, but there are also need large upfront investment and the effective return appears slowly, so that the general economic situation is far behind in the land.

Most islands' area are small and have single resource types, and even larger islands' resources are not complete, besides, the island itself market capacity is limited, not only need input a lot of material resources but also the products need to be sold off-island market in order to develop the island economy. Therefore, the island economy has a natural extroversion. The higher degree of the island economic development, the higher extraversion or external dependence it has, so it is typical resource economics and dependent economy.

\section{PROBLEMS MUST BE NOTED THAT IN THE PROCESS OF DEVELOPMENT AND UTILIZATION}

Disorderly development use of the island in China's coastal areas, not only damage the island's ecological functions but also seriously polluted the island's environment, moreover, the island resources have been wantonly developed and occupied, these acts have negative effect on implementing the marine development strategy [5]. Therefore, it is very necessary to strengthen the development and management of uninhabited island and make sure all development activities are included in the protection of the premise.

\section{A. Must be prepared to plan and to strengthen management}

Since most of the uninhabited island's area is small, away from the mainland, traffic inconvenience, and no one is interested in long-term, without any form of development and pollution, the uninhabited island presents tremendous potential for development. However, management's negligence has led to the uninhabited islands development disorder, independent, arbitrary, resulting in the ecological environment pollution and destruction of the island [6].

The majority development model of uninhabited island is engaged in marine aquaculture, development of island tourism, construction fishing port, the port industry, warehousing base and so on. Such development and utilization generally has problem such as blindness extensive development, development level is not high enough and low economic efficiency. And sometimes even arisen acts like bombing island, reef explosion, reclamation to make tombolo and embankments, mount quarry, in order to seek quick returns and instant benefits, resulting in the devastation of many uninhabited islands' resources and ecological environment.

The management of uninhabited island's environmental involves a wide range, and there are many issues came before the introduction of the "Island Protection Act" and left over from history [7], so need a good plan to strengthen management, and to seek support and cooperation in all sectors of society.

\section{B. Must pay attention to the construction of infrastructure}

The uninhabited island is an important part of our territory, and its social, economic, political and military value is immeasurable [8]. The island's protection and management need to be worked around the island regional economic and social development [9]. To take full advantage of uninhabited islands, whether as outposts of the national maritime strategy, or to obtain economic benefits of tourism development, the infrastructure construction is essential.

Uninhabited island infrastructure construction generally has problems such as need a large amount of investment, maintenance costs high. To promote uninhabited island's strategic position and use value, it is important to focus on investment in building infrastructure and other supporting facilities on the island, including the road traffic system, power supply systems, water supply and drainage systems, sewage treatment system..

\section{Must focus on protecting the ecological environment}

Most of uninhabited islands far away from the mainland and separated by the sea, each island is an independent and complete regional ecosystem [10]. Nevertheless, materials and electricity, etc. all rely on external transport as the island lack of resources. Furthermore, the island's capacity of absorptive garbage is limited. So construction uninhabited island's must firmly establish the awareness of environmental conservation, make great efforts to transform resource-saving, quality and economic, and achieve ecological harmony and unity.

- $\quad$ Reduce the use of non-renewable resources such as coal, oil, electricity. To achieve energy savings, we can selective construction small wind power stations, using solar water heaters, installing solar lighting in public places, and using induction energy-saving lamps, energy saving and environmentally friendly materials and other measures according to the uninhabited islands' climate characteristics.

- Reasonable use of the island's freshwater resources. In order to improve water use efficiency and form good situation of water resources recycling, we can take measures such as receiving water through the roof, constructing pool of rainwater harvesting, processing purification secondary use of sewage, installing water-saving devices and so on. 
- Give full consideration to the island's natural carrying capacity. Implement environmental protection measures and robust governance sources of pollution, insist on governance and management, with pesticides and benefit simultaneously, to deal with the heavy pollution and harm of the boiler's waste gas, wastewater, waste residue. Through effective measures like eliminating the smoke and dust, sewage treatment, garbage removal, to make total control and safe disposal, so that meet the national emission standards and minimize the impact of uninhabited island's ecological environment.

\section{Summary}

All in all, the uninhabited island should be moderate development, formulate different development and construction program for different geographical environment island, make sure the pace of development and construction has always been to match the intensity of protection, and establish the overall concept and perspective when developing them.

In addition, we should strengthen management, adhere to the development and protection, pay attention to the infrastructure construction, reasonable use resources as well as fully consider the island's natural carrying capacity, in order to promote the balanced development of their economic, social, ecology.

\section{REFERENCES}

[1] Qingsong Zhang: The Construction of uninhabited islands the use rights system. Legal System and Society, 2012(3) 33-34

[2] Jinke Li: The development of uninhabited islands also should take the road of sustainable development. Ocean Development and Management, 2004,21(1)47-50

[3] Boen Li: The legal thinking of the uninhabited island's land resources development and rational utilization. LAND \& RESOURCES, 2004(1) 28-30

[4] Yin Li, Guangquan Kang: Problems of Protection and Utilization of the Non-Living Island. Ocean Development and Management, 2003(6) 29-31

[5] Zhilin Mu: The Necessities of Island Legislation on the Grounds of Unique Ecological System and Natural Resources on Islands. Ocean Development and Management, 2007,24(2) 44-46

[6] Qiaozhi Li: Studies on the key problems concerning the management of uninhabited islands. Marine Information, 2004(4) 16-20

[7] Xiuli Fan: The legal issues research of China uninhabited island environmental protection. Master Journal of Central University for Nationalities, 2010.5

[8] Yuan Guo: A thinking of uninhabited islands' development and protection. Journal of Ocean University of China (Social Sciences), 2004(3) 20-22

[9] Caixia Lu: On the Unprecedented Opportunities in the Developing Work of Islands Ocean. Development and Management, 2009,26(3) 9-10

[10] Liqing Ma: The uninhabited islands' development and protection of tourism resources. Business Economics and Administration, 2009(2) 92-96

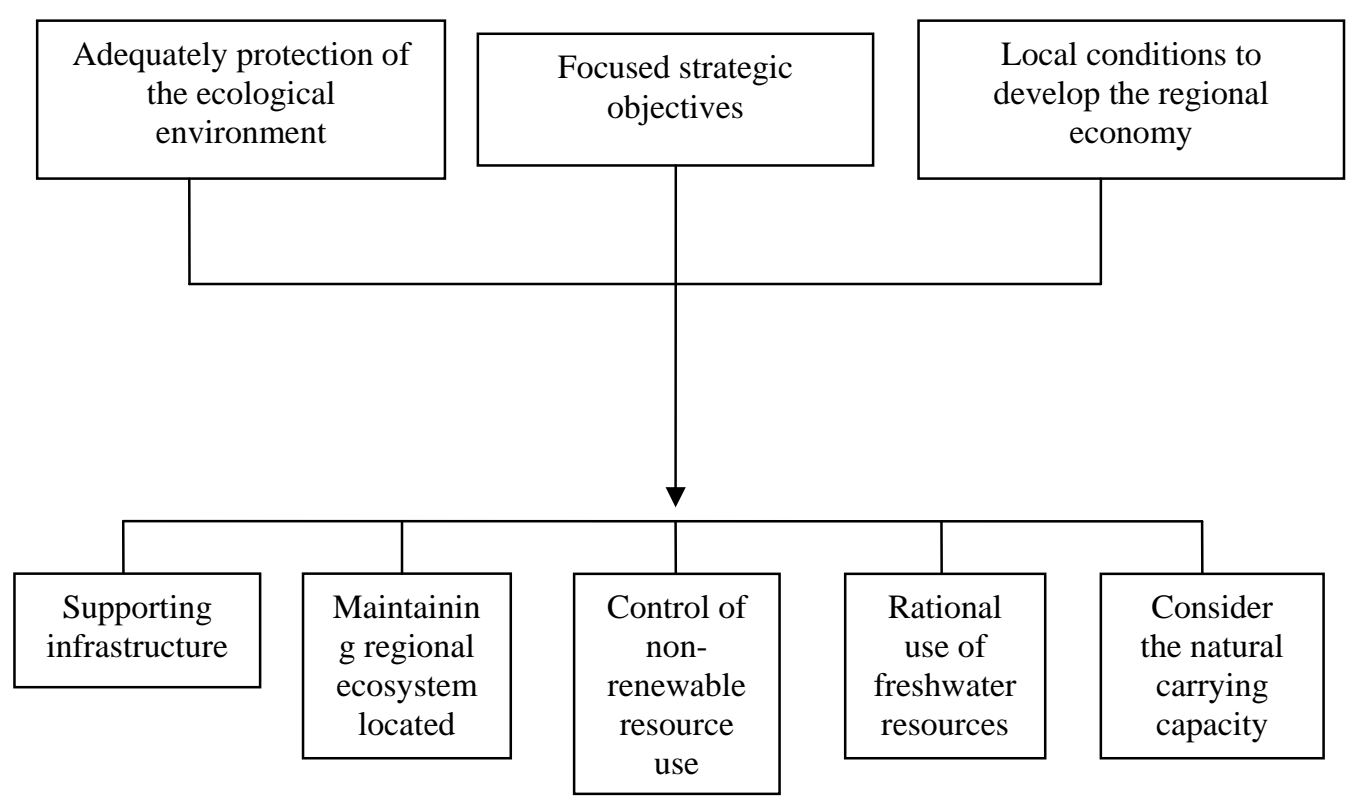

Figure 1. The specific idea. 